\title{
Derecho a la Educación de las niñas, niños y adolescentes en contexto COVID-19
}

\section{Right to Education of Children and Adolescents in the Context of COVID-19}

\author{
Leonardo Toapanta-Jiménez \\ us.leonardotoapanta@uniandes.edu.ec \\ Universidad Regional Autónoma de los Andes, Santo Domingo \\ Ecuador \\ https://orcid.org/0000-0002-9489-8637 \\ Wellington Alexander Bustos-Venegas \\ wellingtonb1997@hotmail.com \\ Universidad Regional Autónoma de los Andes, Santo Domingo \\ Ecuador \\ https://orcid.org/0000-0002-9884-9875
}

Recepción: 15 de septiembre 2021

Revisado: 25 octubre 2021

Aprobación: 15 de noviembre 2021

Publicación: 01 de diciembre 2021 


\title{
RESUMEN
}

En la presente investigación, se planteó como objetivo, analizar jurídica y doctrinariamente el derecho a la educación de las niñas, niños y adolescentes en contexto COVID-19. La modalidad de investigación se basó en el paradigma cuantitativo, con una metodología de tipo descriptiva documental-bibliográfica, con apoyo del método analítico-sintético. Se utilizó como técnica la encuesta la cual fue aplicada a una muestra de 95 padres de familia, de la parroquia San Jacinto del Búa, del cantón Santo Domingo. De acuerdo a los resultados se evidenció que existe preocupación en los padres de familia puesto que, primero, la pandemia les limitó acceder al derecho a la educación, y segundo, por cuanto mencionan que no han existido políticas públicas del Ministerio de Educación. Se concluye, que el Ministerio de Educación deberá realizar los esfuerzos necesarios para controlar los efectos de la pandemia y evitar la privación del aprendizaje y la deserción escolar.

Descriptores: Derecho a la educación; virus; pandemia; niñez; adolescencia. (Palabras tomadas de Tesauro UNESCO).

\begin{abstract}
In this research, the objective was to analyze legally and doctrinally the right to education of girls, boys and adolescents in the COVID-19 context. The research modality was based on the quantitative paradigm, with a documentary-bibliographic descriptive methodology, supported by the analytical-synthetic method. The survey was used as a technique, which was applied to a sample of 95 parents, from the San Jacinto del Búa parish, of the Santo Domingo canton. According to the results, it was evidenced that there is concern among parents since, first, the pandemic limited their access to the right to education, and second, because they mention that there have been no public policies of the Ministry of Education. It is concluded that the Ministry of Education must make the necessary efforts to control the effects of the pandemic and avoid the deprivation of learning and school dropouts.
\end{abstract}

Descriptors: Education rights; virus; pandemic; childhood; adolescence (words takenfrom UNESCO Thesaurus). 


\section{INTRODUCCIÓN}

Por medio del proceso de enseñanza se busca el favorecimiento del aprendizaje y formación desde la instrucción y transversalidad curricular, mediante la capacidad de instituir una cultura desde la gestión del conocimiento, en este sentido Martínez Castillo (2010) define la educación de la siguiente forma:

La educación es un proceso de transmisión de conocimientos y actitudes, sirve como un instrumento básico para transmitir los rasgos fundamentales de la cultura, las técnicas vitales para la sociedad y un conjunto de actitudes, normas, valores y otros, por eso sirve para un cambio sustentable. (p.86)

Por ello, la educación se ha transformado en uno de los ejes más significativos y esenciales para los procesos de trasformación de una sociedad, ya que es la gerente del campo pedagógico, formativo, didáctico del ser humano y de desarrollar en cierta medida su potencial creativo.

En este sentido, el derecho a la educación históricamente ha tenido gran repercusión y transcendencia a nivel social y cultural. Jurídicamente en el caso de Ecuador, la educación se encuentra garantizada en la Carta Magna como uno de los deberes primordiales del Estado, lo que le confiere rango constitucional y de obligatoriedad cumplimiento. Por ello Montero (2015) se refiere:

En cuanto a garantizar el derecho constitucional a la educación dentro de la política pública del buen vivir en el ordenamiento jurídico ecuatoriano, de acuerdo con la doctrina se puede señalar que el derecho a la educación es innato de toda persona, es más, toda persona nace con ese derecho de ser parte del sistema nacional educativo. (p.104)

Es así como, en el Ecuador la educación se enmarca a nivel inicial, básico y bachillerato o su equivalente. Frente a esto, la carta magna reconoce a las niñas, niños y adolescentes como un grupo de atención prioritaria y les garantiza otros derechos. Al respecto, la Ley Orgánica de educación Intercultural (2011) establece:

Artículo. 5.- La educación como obligación de Estado. - El Estado tiene la obligación ineludible e inexcusable de garantizar el derecho a la educación, a los habitantes del territorio ecuatoriano y su acceso universal a lo largo de la vida, para lo cual generará las condiciones que garanticen la igualdad 
de oportunidades para acceder, permanecer, movilizarse y egresar de los servicios educativos. El Estado ejerce la rectoría sobre el Sistema Educativo a través de la Autoridad Nacional de Educación de conformidad con la Constitución de la República y la Ley.

Por otro lado, en el año 2019 la pandemia del COVID-19 apareció en el continente asiático, causando estragos en todo el panorama mundial a partir del mes de febrero del 2020, de lo cual Ecuador no fue la excepción. Las consecuencias de esta pandemia no solamente fueron a nivel de salubridad, política y economía, sino que, también se vio afectado el derecho a la salud y educación de los ciudadanos.

En este orden de ideas, el gobierno ecuatoriano se vio obligado a disponer medidas de confinamiento, que causo el cierre permanente de escuelas y colegios, a fin de evitar la propagación del virus. En este orden de ideas, mediante Decreto Presidencial No. 1017 con fecha 17 de marzo de 2020, se declaró a la República del Ecuador en Estado de Emergencia, en tal virtud que la ciudadanía pudo vivenciar la desigualdad con relación a la realidad social en el ámbito de salud, economía, educación, en todo el territorio, en donde los habitantes se vieron mermados de realizar sus actividades cotidianas en ámbito general de toda la población.

Con estos antecedentes, se optó por el uso de las tecnologías de la información y comunicación en el sistema educativo, como el uso de plataformas digitales y correos institucionales, clases por video conferencia y foros en vivo, a fin de no impedir que se detenga el desarrollo de la educación. Estas medidas fueron adoptadas por las escuelas, colegios y universidades en todo el Ecuador. Sin embargo, el problema no solo fue la propagación del COVID-19, sino que también, se limitó el acceso a la educación de muchos estudiantes. A nivel general, el Instituto Nacional de Estadísticas y Censos (INEC) presentó los datos sobre el uso de las tecnologías de la información y comunicación 2019, las cifras del último informe en dicho aspecto evidencian que en el país aún existe desigualdad tanto en el acceso a recursos tecnológicos como a servicios. 
En consecuencia, la legislación del país ecuatoriano garantiza el derecho educativo de sus niños, niñas y adolescentes:

\section{Cuadro 1.}

Normas vigentes.

\begin{tabular}{|c|c|}
\hline Cuerpo legal & Desarrollo \\
\hline Constitución de la republica del ecuador (2008) & $\begin{array}{l}\text { Artículo 3.- Son deberes primordiales del } \\
\text { Estado: } \\
\text { 1. Garantizar sin discriminación alguna el } \\
\text { efectivo goce de los derechos establecidos en } \\
\text { la Constitución y en los instrumentos } \\
\text { internacionales, en particular la educación, la } \\
\text { salud, la alimentación, la seguridad social y el } \\
\text { agua para sus habitantes. } \\
\text { Artículo 26.- La educación es un derecho de las } \\
\text { personas a lo largo de su vida y un deber } \\
\text { ineludible e inexcusable del Estado. Constituye } \\
\text { un área prioritaria de la política pública y de la } \\
\text { inversión estatal, garantía de la igualdad e } \\
\text { inclusión social y condición indispensable para } \\
\text { el buen vivir. Las personas, las familias y la } \\
\text { sociedad tienen el derecho y la responsabilidad } \\
\text { de participar en el proceso educativo. } \\
\text { Artículo } 46 .- \text { El Estado adoptará, entre otras, las } \\
\text { siguientes medidas que aseguren a las niñas, } \\
\text { niños y adolescentes: } \\
\text { 1. Atención a menores de seis años, que } \\
\text { garantice su nutrición, salud, educación y } \\
\text { cuidado diario en un marco de protección } \\
\text { integral de sus derechos. }\end{array}$ \\
\hline Código de la Niñez y Adolescencia (2003) & $\begin{array}{l}\text { Artículo 26.- Derecho a una vida digna. - Los } \\
\text { niños, niñas y adolescentes tienen derecho a } \\
\text { una vida digna, que les permita disfrutar de las } \\
\text { condiciones socioeconómicas necesarias para } \\
\text { su desarrollo integral. } \\
\text { Este derecho incluye aquellas prestaciones que } \\
\text { aseguren una alimentación nutritiva, equilibrada } \\
\text { y suficiente, recreación y juego, acceso a los } \\
\text { servicios de salud, a educación de calidad, } \\
\text { vestuario adecuado, vivienda segura, higiénica } \\
\text { y dotada de los servicios básicos. } \\
\text { Artículo 37.- Derecho a la educación. Los } \\
\text { niños, niñas y adolescentes tienen derecho a } \\
\text { una educación de calidad. Este derecho } \\
\text { demanda de un sistema educativo que: } \\
\text { 1.Garantice el acceso y permanencia de todo } \\
\text { niño y niña a la educación básica, así como del } \\
\text { adolescente hasta el bachillerato o su } \\
\text { equivalente; }\end{array}$ \\
\hline
\end{tabular}




\begin{tabular}{|c|c|}
\hline & $\begin{array}{l}\text { 2.Respete las culturas y especificidades de } \\
\text { cada región y lugar; } \\
\text { 3.Contemple propuestas educacionales } \\
\text { flexibles y alternativas para atender las } \\
\text { necesidades de todos los niños, niñas y } \\
\text { adolescentes, con prioridad de quienes tienen } \\
\text { discapacidad, trabajan o viven una situación } \\
\text { que requiera mayores oportunidades para } \\
\text { aprender; } \\
\text { 4.Garantice que los niños, niñas y adolescentes } \\
\text { cuenten con docentes, materiales didácticos, } \\
\text { laboratorios, locales, instalaciones y recursos } \\
\text { adecuados y gocen de un ambiente favorable } \\
\text { para el aprendizaje. Este derecho incluye el } \\
\text { acceso efectivo a la educación inicial de cero a } \\
\text { cinco años, y por lo tanto se desarrollarán } \\
\text { programas y proyectos flexibles y abiertos, } \\
\text { adecuados a las necesidades culturales de los } \\
\text { educandos; y, } \\
\text { 5. Que respete las convicciones éticas, morales } \\
\text { y religiosas de los padres y de los mismos } \\
\text { niños, niñas y adolescentes. } \\
\text { La educación pública es laica en todos sus } \\
\text { niveles, obligatoria hasta el décimo año de } \\
\text { educación básica y gratuita hasta el bachillerato } \\
\text { o su equivalencia. } \\
\text { El Estado y los organismos pertinentes } \\
\text { asegurarán que los planteles educativos } \\
\text { ofrezcan servicios con equidad, calidad y } \\
\text { oportunidad y que se garantice también el } \\
\text { derecho de los progenitores a } \\
\text { elegir la educación que más convenga a sus } \\
\text { hijos y a sus hijas. }\end{array}$ \\
\hline $\begin{array}{l}\text { Ley Orgánica de Garantías Jurisdiccionales y } \\
\text { Control Constitucional (2009) }\end{array}$ & $\begin{array}{l}\text { Artículo. 1.- Objeto y finalidad de la ley. Esta ley } \\
\text { tiene por objeto regular la jurisdicción } \\
\text { constitucional, con el fin de garantizar } \\
\text { jurisdiccionalmente los derechos reconocidos } \\
\text { en la Constitución y en los instrumentos } \\
\text { internacionales de derechos humanos y de la } \\
\text { naturaleza; y garantizar la eficacia y la } \\
\text { supremacía constitucional. }\end{array}$ \\
\hline Ley Orgánica de Educación Intercultural (2011) & $\begin{array}{l}\text { Artículo 6.- Obligaciones. - -La principal } \\
\text { obligación del Estado es el cumplimiento pleno, } \\
\text { permanente y progresivo de los derechos y } \\
\text { garantías constitucionales en materia } \\
\text { educativa, y de los principios y fines } \\
\text { establecidos en esta Ley. } \\
\text { El Estado tiene las siguientes obligaciones } \\
\text { adicionales: } \\
\text { a.Garantizar, bajo los principios de equidad, } \\
\text { igualdad, no discriminación y libertad, que todas } \\
\text { las personas tengan acceso a la educación } \\
\text { pública de calidad y cercanía; }\end{array}$ \\
\hline
\end{tabular}




\begin{tabular}{|l|l|}
\hline & b.Garantizar que las instituciones educativas \\
sean espacios democráticos de ejercicio de \\
derechos y convivencia pacífica; \\
i.Impulsar los procesos de educación \\
permanente para personas adultas y la \\
erradicación del analfabetismo puro, funcional y \\
digital, y la superación del rezago educativo; \\
j.Garantizar la alfabetización digital y el uso de \\
las tecnologías de la información y \\
comunicación en el proceso educativo, y \\
propiciar el enlace de la enseñanza con las \\
actividades productivas o sociales...
\end{tabular}

Elaboración: Los autores.

Se planteó como objetivo, analizar jurídica y doctrinariamente el derecho a la educación de las niñas, niños y adolescentes en contexto COVID-19.

\section{METODOLOGÍA}

La modalidad de investigación se basó en el paradigma cuantitativo, con una metodología de tipo descriptiva documental-bibliográfica, con apoyo del método analítico-sintético la cual se aplicó al utilizar fuentes teóricas de información jurídica, normativas, doctrinas, sobre el tema de la educación en las niñas, niños y adolescentes. Construyendo un cuerpo reflexivo teórico como tributo y fortalecimiento del basamento teórico-jurídico del derecho, para alcanzar el objetivo planteado se reflexionaron los pasos presentados por los autores Hernández Sampieri, et al. (2014). Se utilizó como técnica la encuesta la cual fue aplicada a una muestra de 95 padres de familia, de la parroquia San Jacinto del Búa, del cantón Santo Domingo. 


\section{RESULTADOS}

A continuación, se representan los resultados de la encuesta aplicada a una muestra de 95 padres de familia de la parroquia San Jacinto del Búa.

1) ¿Cuál es la afectación del COVID-19 en San Jacinto del Búa?

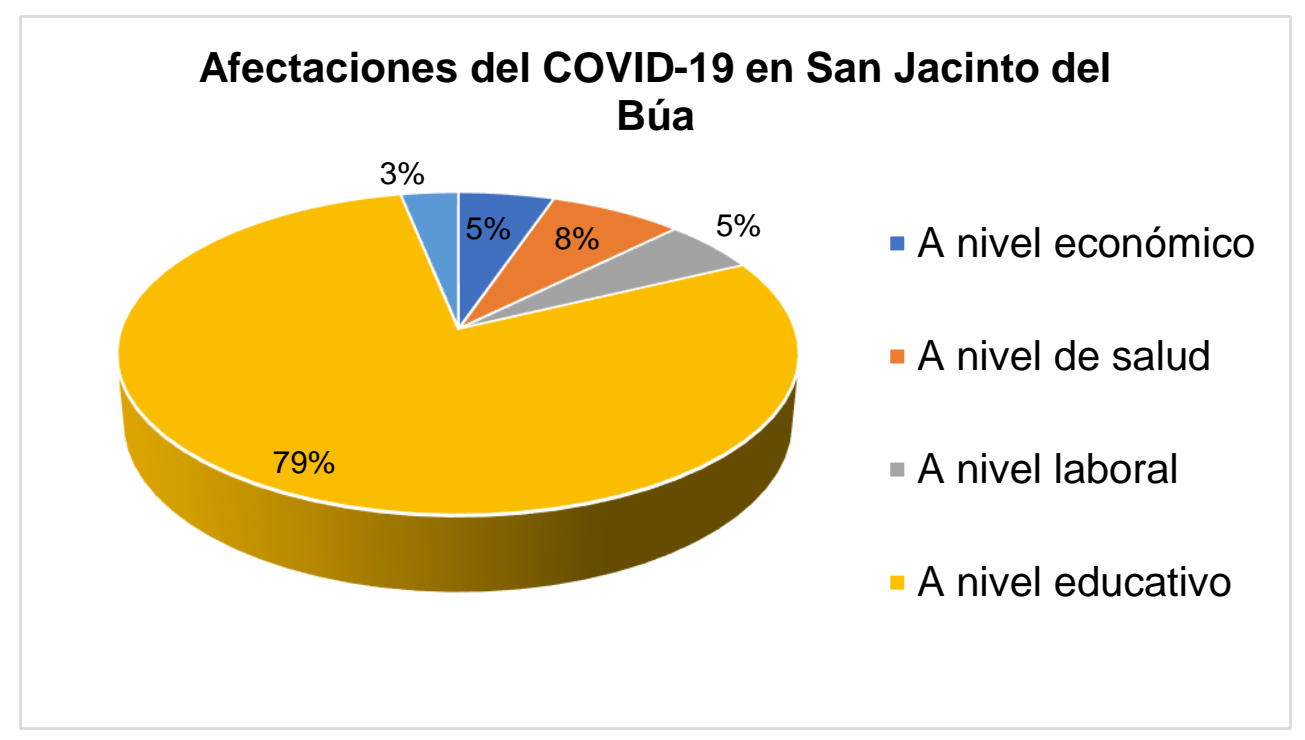

\section{Gráfica 1.}

Fuente: Encuesta.

De los datos estadísticos obtenidos a la primera interrogante el $79 \%$ de los encuestados manifiestan que las afectaciones del COVID-19 en San Jacinto del Búa son mayores a nivel educativo, por cuanto las limitaciones existentes en la actualidad y su difícil acceso impiden el desarrollo u ejercicio de este derecho a un importante grupo de atención. 
2) ¿Cuál es la Importancia de la educación en San Jacinto del Búa?

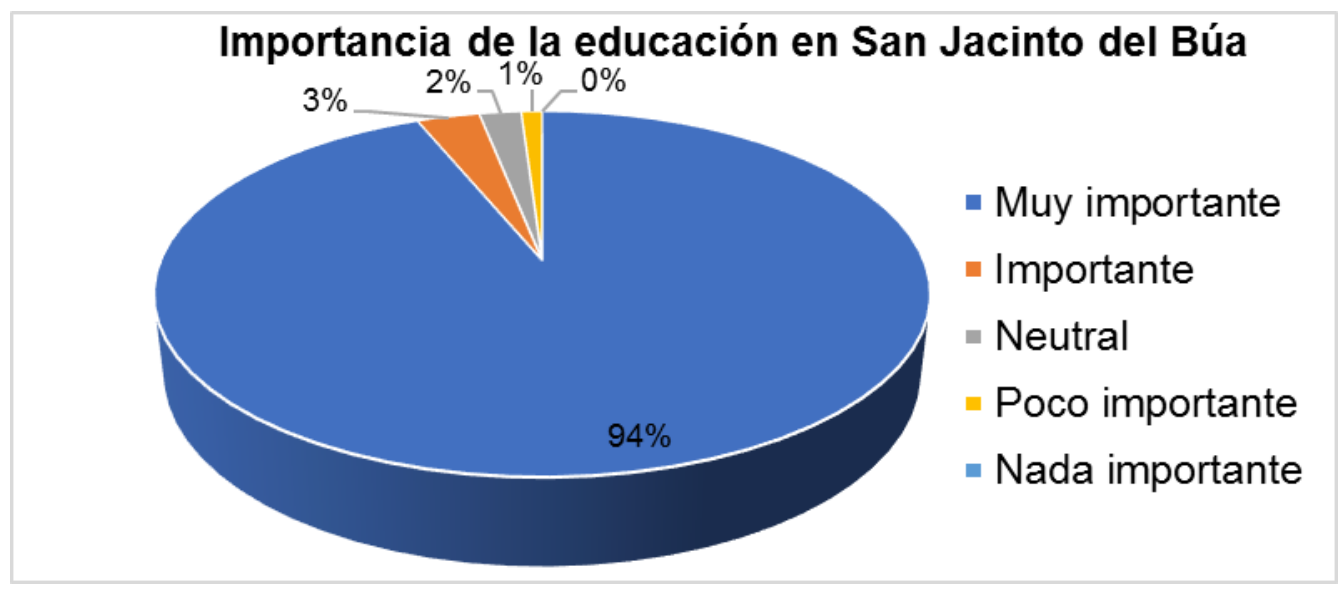

\section{Gráfica 2.}

Fuente: Encuesta.

De los datos estadísticos obtenidos a la segunda interrogante el $94 \%$ de los encuestados manifiestan que en la parroquia San Jacinto del Búa, consideran muy importante la educación en comparación al 1\% de la población encuestada debido a las consecuencias del COVID-19 considera que es poco importante la educación dentro de la parroquia.

3) ¿A pesar de la pandemia del COVID-19, sus hijos estudian?

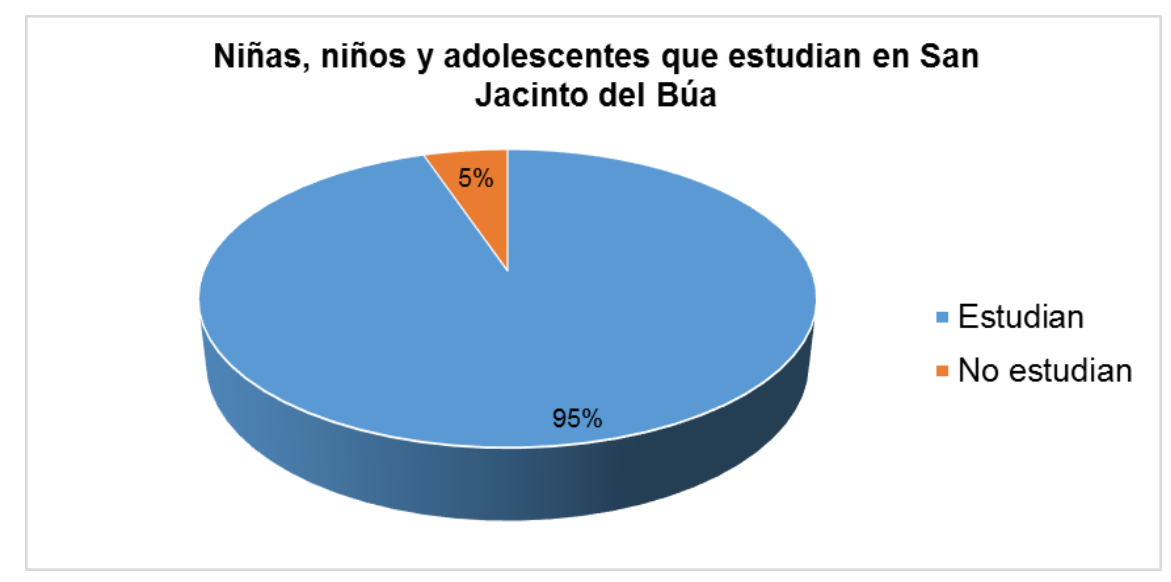

\section{Gráfico 3.}

Fuente: Encuesta. 
De los datos estadísticos obtenidos a la tercera interrogante el $95 \%$ de los encuestados se pronuncian manifestando que a pesar de la pandemia del COVID-19, sus hijos estudian por medio de internet lo que ha ayudado a que los niños, niñas y adolescentes de la parroquia San Jacinto del Búa a diferencia de que el 5\% de los menores de esta parroquia no se encuentran estudiando.

4) ¿Qué horario de estudio prefieren los niños, niñas y adolescentes, para su desarrollo?

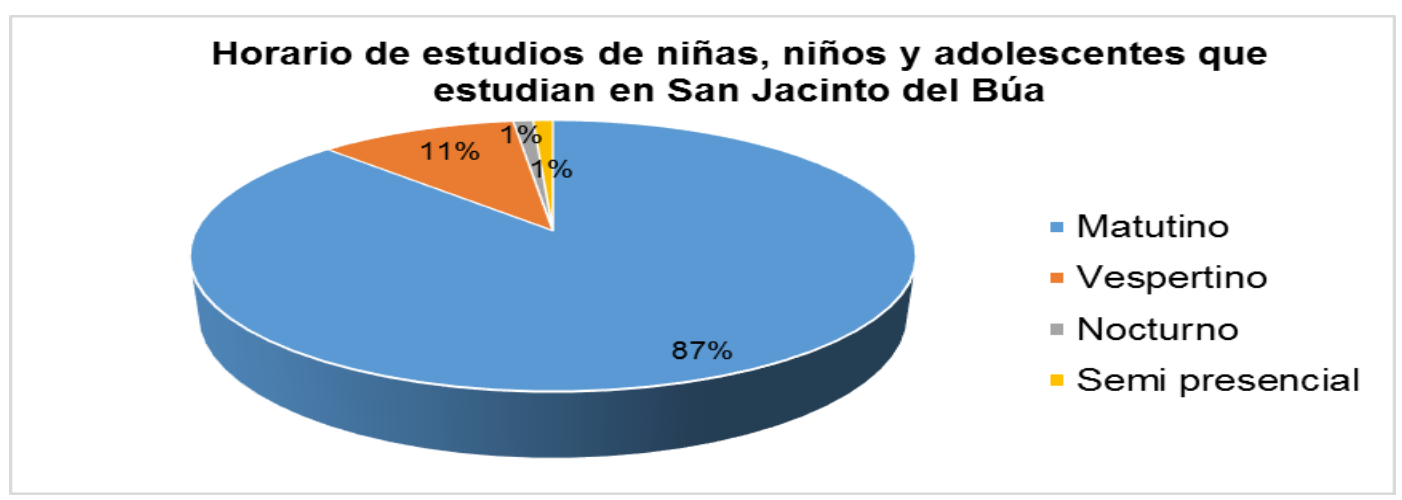

\section{Gráfico 4.}

Fuente: Encuesta.

De los datos estadísticos obtenidos a la cuarta interrogante el $87 \%$ de la población encuestada en la parroquia San Jacinto del Búa, mencionan que prefieren el horario matutino para el desarrollo de los estudios de los niños, niñas y adolescentes, así también el $11 \%$ consideran que es mejor el horario vespertino. 
5) ¿Tienen acceso a internet?

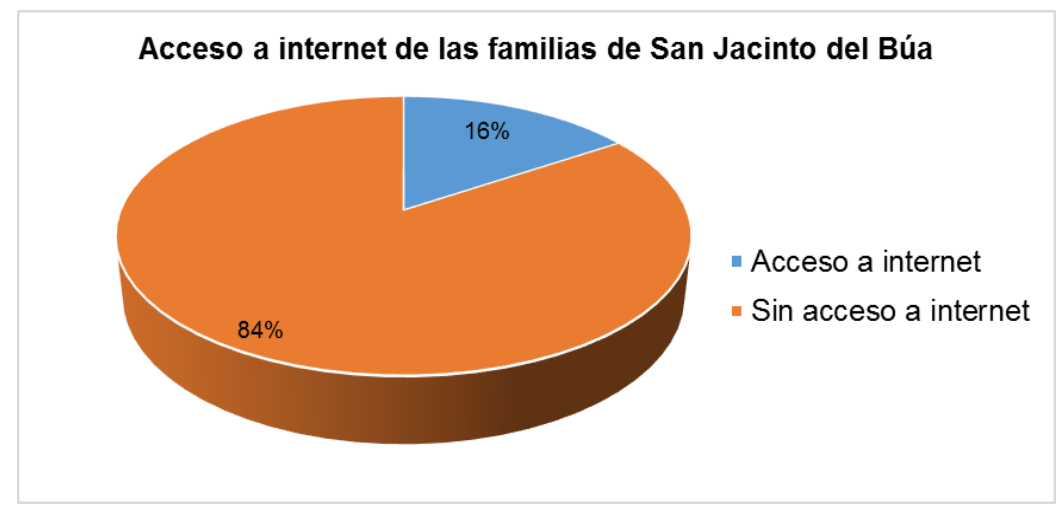

\section{Gráfico 5.}

Fuente: Encuesta.

De los datos estadísticos obtenidos a la quinta interrogante el $84 \%$ de los encuestados determina que si tienen acceso a internet en la parroquia San Jacinto del Búa y tan solo el $16 \%$ considera que debido a la pandemia del COVID-19 no tiene acceso a internet dentro de la parroquia.

6) ¿Cuál es el tiempo en el que sus hijos estuvieron sin estudiar?

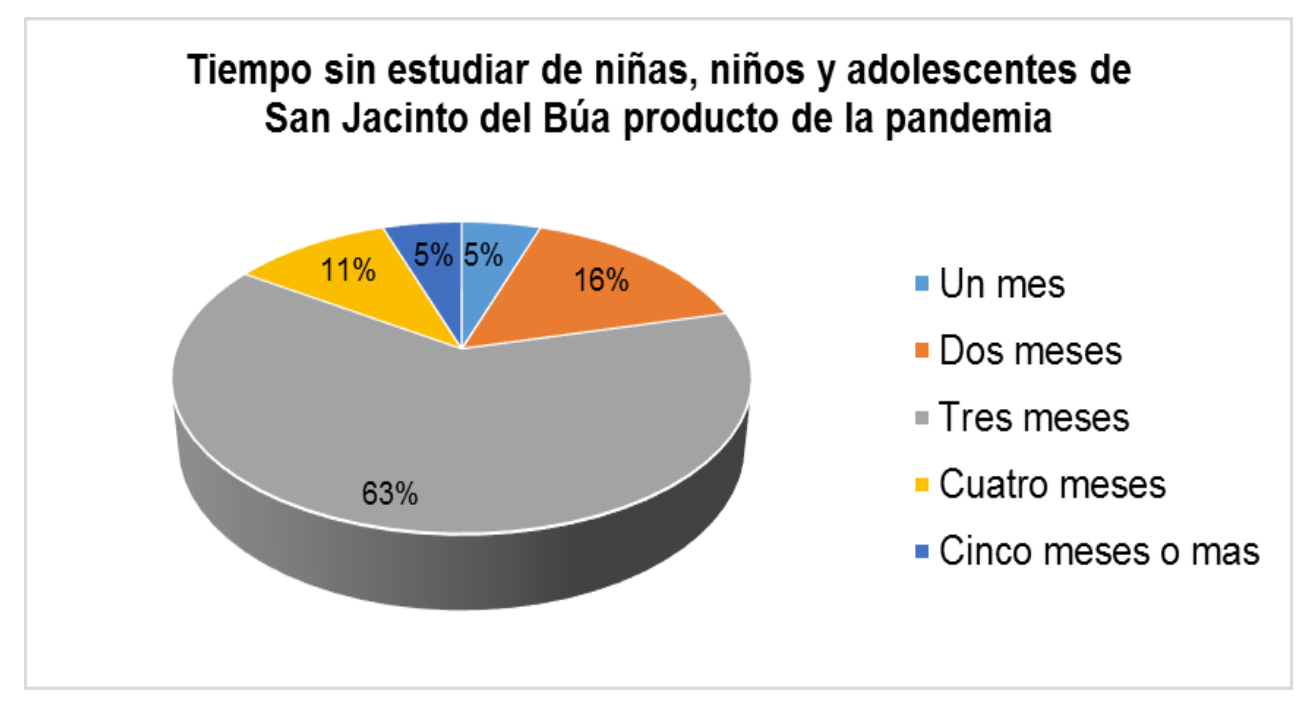

\section{Gráfico 6.}

Fuente: Encuesta. 
De los datos estadísticos obtenidos a la sexta interrogante el 63\% de los encuestados manifiesta que al menos tres meses fue el tiempo en el que sus hijos estuvieron sin estudiar, lo que es relevante puesto que el tiempo que se plantea en la presente variable determina que debido a la pandemia de COVID-19 el 100\% de la población tuvo a los niños, niñas y adolescentes privados del derecho a la educación desde un mes hasta cinco meses o más.

7) ¿El Ministerio de Educación, promueve políticas públicas en el sector que permitan fomentar la educación?

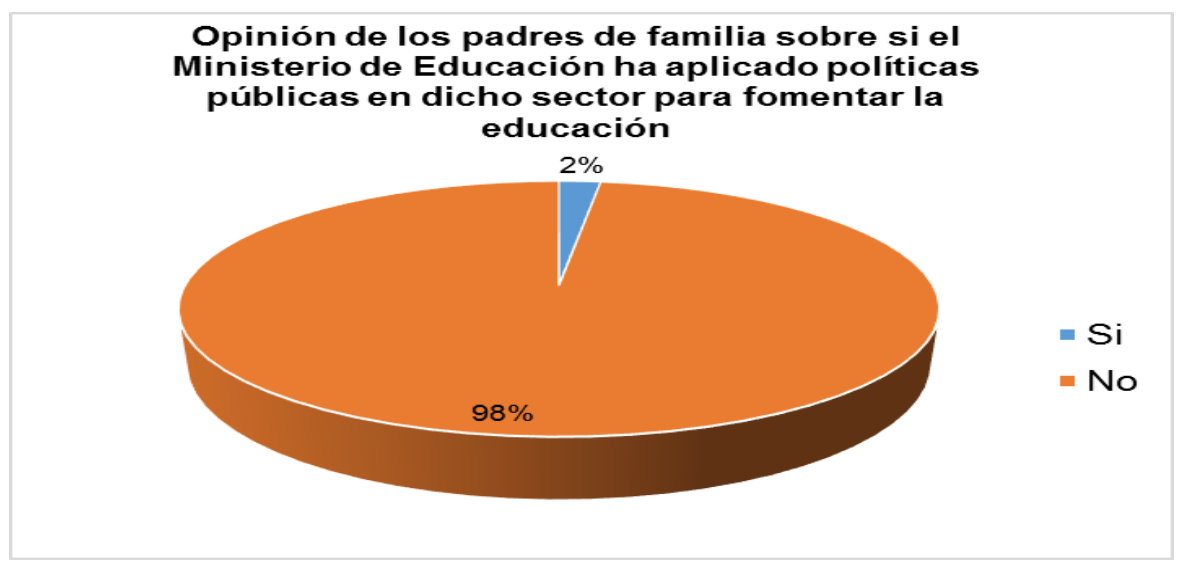

\section{Gráfico 7.}

Fuente: Encuesta.

De los datos estadísticos obtenidos a la séptima interrogante el $98 \%$ de la población encuestada manifiesta que en la parroquia San Jacinto del Búa, el Ministerio de Educación no se ha pronunciado o a aplicado políticas públicas en el sector que permitan fomentar la educación más aun debido a la pandemia de COVID-19.

\section{DISCUSIÓN}

La educación como derecho, se configura en uno de los más importantes para el ser humano y mucho más para las niñas, niños y adolescentes, por cuanto les permite alcanzar y adquirir nuevos conocimientos; dicha premisa fue ratificada por los padres de familia encuestados, quienes opinaron unívocamente que están preocupados por 
el derecho a la educación de sus niñas, niños y adolescentes, ya que consideran que no se goza plenamente de esto, por circunstancias económicas o tecnológicas.

Ahora bien, desde el inicio de la pandemia, fue evidente que las clases tenían que suspenderse a fin de evitar los contagios en los centros educativos, donde la carga viral a nuestra consideración resulta ser más alta, teniendo en cuenta la vulnerabilidad de las niñas, niños y adolescentes por sus características biológicas, así como considerando el espacio donde regularmente reciben clases y el constante contacto masivo que hay en los estudiantes. Frente a esto, el Ministerio de Educación del Ecuador mediante el Acuerdo N MINEDUC-MINEDUC-2020-00014-A, resuelve la suspensión de clases en todo el territorio nacional, en todas sus jornadas y modalidades y dispone al personal administrativo y docente del Sistema Nacional de Educación, continuar sus labores mediante la modalidad de teletrabajo de acuerdo con la normativa que el ente rector del trabajo expida para el efecto (Ministerio de Educación, 2020).

De acuerdo a los resultados de la encuesta evidenció que existe preocupación en los padres de familia de la parroquia San Jacinto del Búa del cantón Santo Domingo, puesto que, primero, la pandemia les limitó acceder al derecho a la educación, y segundo, por cuanto mencionan que no han existido políticas públicas del Ministerio de Educación en dicho sector para fomentar un correcto proceso educativo remoto, donde se denota la inconformidad de esta comunidad por la falta de iniciativa del órgano competente.

Así mismo, los padres de familia encuestados mencionaron que sin duda alguna, el aspecto económico fue el más perjudicado a nivel nacional y mundial, sin embargo en su sector, la educación resulto más afectada, no es menos cierto que los efectos económicos y de salubridad del COVID-19 también se vieron reflejados en dicho sector, empero de lo cual mostraron su preocupación de forma univoca respecto de la educación de sus niñas, niños y adolescentes, quienes manifestaron que un 95\% de dicho recinto estudian, de los cuales un $87 \%$ estudian de en modalidad matutina y un $11 \%$ en vespertina. De ellos, la encuesta reveló que solo $84 \%$ tiene acceso a internet. 
Este porcentaje es suministrado a través de WIFI producto de diferentes empresas privadas.

\section{CONCLUSIONES}

Al concluir la investigación, se destaca la importancia jurídica y social del derecho constitucional a la educación de las niñas, niños y adolescentes, delimitando su vigencia y observancia en el contexto del COVID-19 donde como se observó, muchas de las niñas, niños y adolescentes de la parroquia San Jacinto del Búa, no tuvieron un pleno acceso a este derecho. Con el análisis jurídico realizado se ha evidenciado que la educación desde el punto de vista legal es un derecho que, por su reconocimiento constitucional y convencional, cobra vital importancia en su vigencia y aplicación por parte del estado ecuatoriano y en consecuente surte efecto la premisa de que, el gobierno ecuatoriano a través de la autoridad competente debe elaborar suficientes planes de contingencia y protocolos que permitan una correcta educación remota o presencial.

Sin embargo, en caso de que, el Estado ecuatoriano, a través del Ministerio de Educación, no realice suficientes esfuerzos para controlar los efectos de la pandemia en la educación de niñas, niños y adolescentes, el cierre de escuelas provocará carencia de aprendizajes, aumento en la deserción escolar y una mayor inequidad social en las familias ecuatorianas, a mediano y largo plazo.

\section{FINANCIAMIENTO}

No monetario.

\section{AGRADECIMIENTO}

A la Universidad Regional Autónoma de los Andes, Santo Domingo, por motivar el desarrollo de la Investigación. 


\section{REFERENCIAS CONSULTADAS}

Asamblea Nacional (2017) Ley Orgánica de Educación Intercultural. [Organic Law on Intercultural Education]. Registro Oficial No. 417 de 31 de marzo de 2011. Recuperado de: https://n9.cl/1fo3

Asamblea Nacional (2009) Ley Orgánica de Garantías Jurisdiccionales y Control Constitucional. [Organic Law on Jurisdictional Guarantees and Constitutional Control]. Ley 0 Registro Oficial Suplemento 52 de 22-oct-2009. Oficio No. SAN2009-077.Recuperado de: https://n9.cl/su7v

Asamblea Nacional Constituyente de la República del Ecuador, (2008). Constitución de la República del Ecuador. [Constitution of the Republic of Ecuador]. Montecristi. Registro Oficial 449 de 20-oct-2008. Recuperado de https://n9.cl/sia

Congreso Nacional (2003). Código de la Niñez y Adolescencia. [Code of Childhood and Adolescents]. publicado por Ley No. 100. en Registro Oficial 737 de 3 de enero del 2003. Recuperado de: https://n9.cl/dtrec

Hernández Sampieri, R., Fernández Collado, C., y Batista Lucio, M. (2014) Metodología de la investigación. [Research methodology] Sexta edición. Editorial McGrawHill. Interamericana. México.

Instituto Nacional de Estadística y Censos. (2019). Encuesta Nacional de Empleo, desempleo y subempleo. [National Survey of Employment, Unemployment and Underemployment]. Quito. Recuperado de: https://n9.cl/fwzp4o

Martínez Castillo, R. (2010). La importancia de la educación ambiental ante la problemática actual. [The importance of environmental education in the face of current problems]. Revista Electrónica Educare, 14(1),97-111. Recuperado de: https://n9.cl/hny95

Ministerio de Educación. (2020). Acuerdo Ministerial Nro. MINEDUC-MINEDUC-202000014-A. [Ministerial Agreement No. MINEDUC-MINEDUC-2020-00014-A]. Quito. Recuperado de: https://n9.cl/vagh

Montero, W. (2015). El Derecho Constitucional a la Educación dentro de la Política Pública del Buen Vivir en el Ordenamiento Jurídico Ecuatoriano. [The Constitutional Right to Education within the Public Policy of Good Living in the Ecuadorian Legal System]. Tesis de pregrado. Universidad Central del Ecuador, Quito. Recuperado de: https://n9.cl/w3n0j

Presidencia de la República de Ecuador. (2020). Decreto presidencial № 1017. [Presidential Decree No. 1017]. Recuperdo de: https://n9.cl/f3kkd 
Iustitia Socialis. Revista Arbitrada de Ciencias Jurídicas

Año VI. Vol. VI. N 1. Edición Especial. 2021

Hecho el depósito de Ley: FA2016000064

ISSN: 2542-3371

FUNDACIÓN KOINONIA (F.K). Santa Ana de Coro, Venezuela

Leonardo Toapanta-Jiménez; Wellington Alexander Bustos-Venegas

@2021 por los autores. Este artículo es de acceso abierto y distribuido según los términos y condiciones de la licencia Creative Commons Atribución-NoComercial-Compartirlgual 4.0 Internacional (CC BY-NC-SA 4.0)

(https://creativecommons.org/licenses/by-nc-sa/4.0/). 